\title{
Steriler postoperativer Katheteranschluss bei Lochtuchabdeckung
}

\author{
Wie nach einer transurethralen Resektion der eingelegte Katheter \\ an den Katheterbeutel angeschlossen werden kann, ohne dass dieser \\ kontaminiert wird, sehen Sie in folgendem Tipp.
}

Am OP-Ende transurethraler Resektionen ergibt sich häufig das Problem, dass der eingelegte Katheter auf der sterilen Seite an den Katheterbeutel angeschlossen wird. Bei korrekter Handhabung der „kontinuierlichen Urindrainage“ verläuft er dann durch die Öffnung der verwendeten Lochtuchabdeckung. Im Ergebnis kommt der saubere Katheterbeutel mit seinem Schlauch mit der potenziell mit Blut, Spülflüssigkeit und Sekret kontaminierten Tuchseite in Kontakt - ein unhygienisches Zerreißen der Abdeckung oder die inkorrekte Diskonnektierung des Katheters mit neuerlichem Anschluss außerhalb der Abdeckung scheint unausweichlich.

Hier wenden wir einen einfachen Trick an: Eine (unsterile) Hilfsperson („Springer“) steckt den noch mit der sterilen Kappe versehenen Katheterschlauch von der Patientenseite durch das Lochtuch auf die sterile Seite ( $\bullet$ Abb. 1 ). Der Operateur verbindet Schlauch und Katheter auf der sterilen Seite des Lochtuchs ( $\bullet$ Abb. 2), dann zieht die Hilfsperson den Katheter mit Schlauch wieder auf die Patientenseite (○ Abb.3). Die OP-Abdeckung kann ohne „Wirrwarr“ und Kontamination des Beutels bzw. Schlauchs abgenommen und entsorgt werden.

\section{PD Dr. Andreas Wiedemann}

Korrespondenz:

PD Dr. Andreas Wiedemann Urologische Klinik

Evangelisches Krankenhaus im Diakoniewerk Ruhr gGmbH Lehrstuhl für Geriatrie der Universität Witten/Herdecke Pferdebachstr. 27

58455 Witten

Tel.: 02 302/175-2521

awiedemann@diakonie-ruhr.de

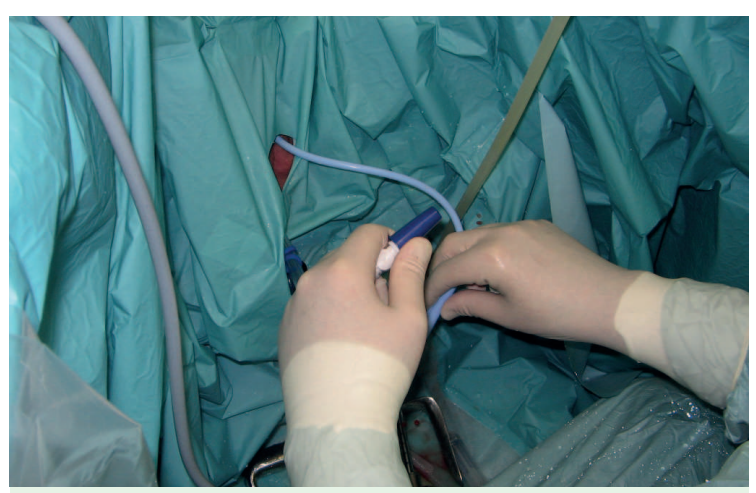

Abb.1 Der Katheterschlauch wird vom „Springer“ von der Patientenseite durchgesteckt.

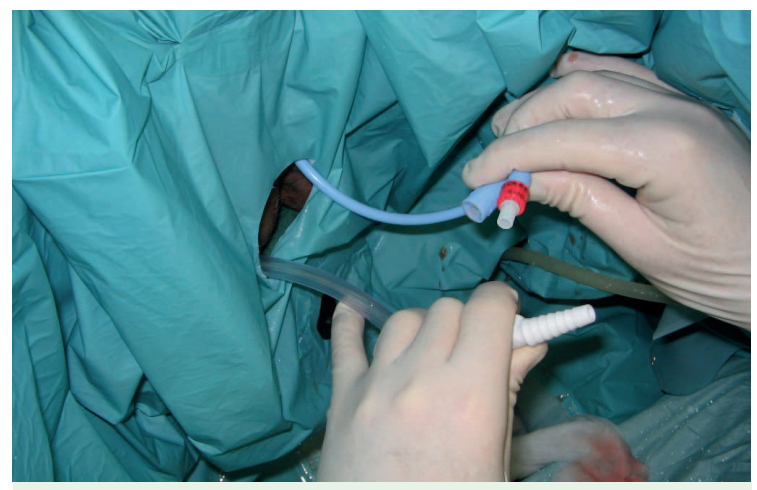

Abb. 2 Der Operateur verbindet Katheter und Schlauch.

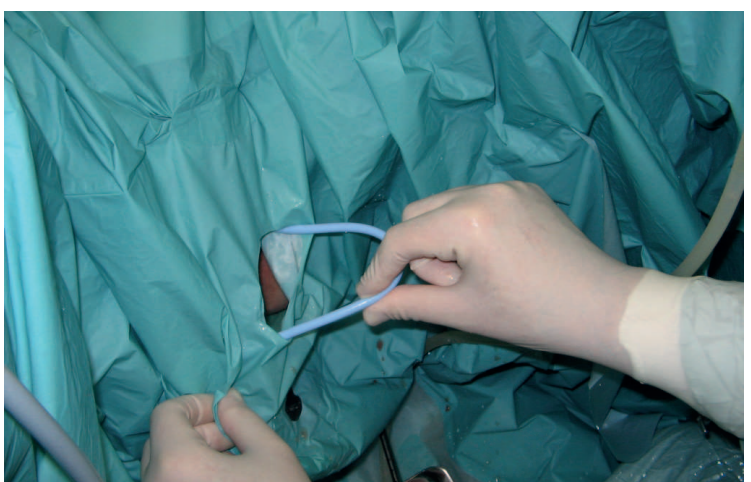

Abb.3 Der „Springer“ zieht den mit dem Katheterbeutel verbundenen Katheter zur Patientenseite nach innen.

Interessenkonflikte: Beratungstätigkeit: Dr. Pfleger, Pfizer; Vortragstätigkeit: Allergan, AMS Deutschland, Astellas, Berlin-
Chemie, Jansen, Lilly Deutschland, Dr. Pfleger, Pfizer, Pohl-Boskamp; Studienfinanzierung: AMS Deutschland 